\title{
Photo-doping of plasma-deposited polyaniline (PAni)
}

Sait Elmas ${ }^{\mathrm{a}}$, Wesley Beelders ${ }^{\mathrm{a}}$, Joseph Nash ${ }^{\mathrm{a}}$, Thomas J. Macdonald ${ }^{\mathrm{b}}$, Marek Jasieniak ${ }^{\mathrm{a}}$, Hans

J. Griesser ${ }^{\mathrm{a}^{*}}$, Thomas Nann ${ }^{\mathrm{a}, \mathrm{c}^{*}}$

${ }^{a}$ Future Industries Institute, University of South Australia, Adelaide, SA 5095, Australia

${ }^{\mathrm{b}}$ Department of Chemistry, University College London, London, England

${ }^{\mathrm{c}}$ MacDiarmid Institute, Victoria University of Wellington, Wellington, 6041, New Zealand

\begin{abstract}
Although polyaniline (PAni) has been studied extensively in the past, little work has been done on producing films of this material via plasma deposition. We have synthesized and analysed the photoresponse behaviour of plasma-deposited polyaniline film and proceeded to dope the films using light and with various metal ions. Upon illumination, the photocurrent responses of the thin plasma films increased over time, and the response was dependent on the film thickness. Doping the film with metal ions, photocurrent densities were enhanced from nano- to micro-amperes per square centimetres. Doping seemed, however, to cause the films to become unstable. Despite this setback, which requires further research, the drastic increase in current shows great promise for the development of plasma-deposited polyaniline films for application in the area of organic electronics and photovoltaics.
\end{abstract}

\section{Keywords}

Conducting polymers, organic semiconductors, plasma enhanced chemical vapor deposition, PECVD, photocurrent, chemical vapor deposition (CVD), polyaniline (PAni), plasma polymerization. 
* send correspondence to: hans.griesser@unisa.edu.au, thomas.nann@vuw.ac.nz.

\section{Introduction}

The development of photosensitive materials based on organic semiconductors has been an attractive approach for energy conversion that uses cheap, abundant and non-toxic materials [1-4]. Using organic semiconductors as opposed to their counterpart, inorganic semiconductors [5-8], opens up many options for flexible and robust devices for a fraction of the cost. Organic semiconductors are being pursued to potentially replace the common silicon photovoltaic devices (PV), which currently dominate the market $[9,10]$, or to find use in niche applications.

Polyaniline (PANI) is a conducting polymer and a promising candidate for use in organic photovoltaics (OPVs) due to its low production cost, semi-flexibility, bio stability and high conductivity [11-15]. To date, polyaniline was most commonly prepared through wet chemical or electrochemical processes [13]. Other synthesis methods include inverse emulsion [16], autocatalysis [17], enzymatic [18] and photochemical polymerization [19]. Many of polyaniline's properties depend on the polymerization process, such as redox state, film thickness and conductivity.

The neutral form of polyaniline has three distinguishable redox states, namely the leucomeraldine base (LB), the emeraldine base (EB) and the pernigraniline base (PNB). As highlighted in Figure 1 the PNB displays the fully oxidized state of polyaniline, which consists of alternating quinonoid and aromatic aniline units. All nitrogen atoms are deprotonated, with quinonoid and aromatic aniline units alternately linked through the imine bond. The LB is the fully reduced and protonated form, which acts as an insulator. The EB is the half-oxidized form of polyaniline, where half of the nitrogen atoms in the polymer chains are deprotonated (Fig. 1). In principle, there is an infinite number of redox states in between LB, EB and LNB, which explains why polyaniline is complex and displays a wide range of properties $[4,20]$. 


\section{Leucomeraldine Base (LB)}

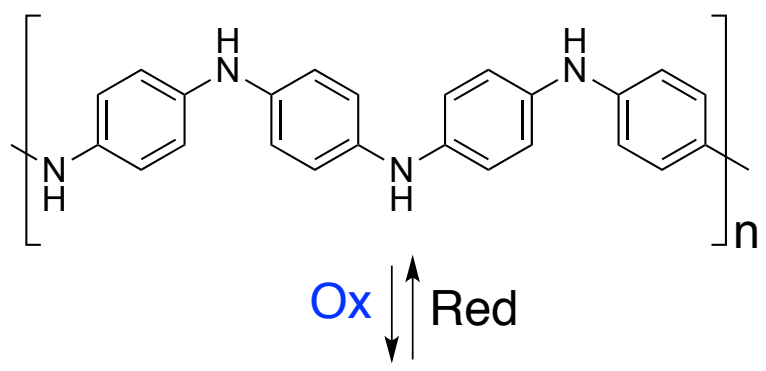

Emeraldine Base (EB)<smiles>CCCCNc1ccc(Nc2ccc(N=C3C=CC(=Nc4ccc(C)cc4)C=C3)cc2)cc1</smiles>

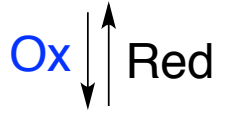

Pernigranilinie Base (PNB)<smiles>CN=C1C=CC(=Nc2ccc(N=C3C=CC(=Nc4ccc(C)cc4)C=C3)cc2)C=C1</smiles>

Figure 1: Chemical structures of the main distinguishable redox states of polyaniline in their neutral form: the leucomeraldine base (LB), the emeraldine base (EB) and the pernigraniline base (PNB).

As synthesized, polyaniline is generally in its most reduced (insulating form) and doping is required to enhance the conductivity [21]. Conventional doping methods include acid treatment (known as non-redox doping) and iodine doping (oxidation). Photo-doping occurs when light pertaining a greater energy than the band gap is used to promote electrons from the valence band into the conduction band causing subsequent oxidation.

Plasma-enhanced chemical vapor deposition (PECVD) is an alternative method to deposit thin films directly from the vapor phase onto a solid-state substrate [22]. When depositing polymeric thin films, the terminology "plasma polymerization" is often used [23]. 
The process is initiated by the application of an alternating electric field across a process vapor comprising volatile organic molecules, which, via a series of chemical reactions in the plasma gas phase, form molecular radicals and ions [24] that react with each other to give thin films deposition. PECVD has a distinct advantage over wet chemical methods by producing thin, cohesive homogenous films [25] that are highly adherent on a variety of surfaces including glass, metals and a variety of other substrates [26]. Plasma polymers are often used as protective coatings [27-30].

Plasma polymerization has been used previously in a few studies to deposit thin polyaniline films [11,31-33] but the resultant films had inferior properties compared with conventionally synthesized ones. In this article we first optimize the plasma deposition conditions towards improved conductance and then show for the first time that PECVD polyaniline can be photo-doped by exposing the films to one sun equivalent of solar light, responding with enhanced photocurrent densities. In-depth analysis of the PECVD film by Xray Photoelectron Spectroscopy (XPS) revealed that the photo-induced doping of plasmapolymerized polyaniline was caused by transformation from an originally reduced species of polyaniline to another form with high grade of oxidation. We also incorporated various metal centres within the film matrix to further enhance or modify the electronic and optical properties.

\section{Experimental}

\subsection{Chemicals}

Aniline (99.5\%), copper(II) chloride hexahydrate, copper(II) sulfate pentahydrate, manganese (II) nitrate tetrahydrate and cobalt (II) nitrate hexahydrate were purchased from Sigma Aldrich and used without further purification. Fluorinated tin oxide (FTO) and gold slides (200 nm Au with $40 \mathrm{~nm}$ Ti sublayer on microscope slides, DRLI Inc. USA) were cut into 2.5 
x $2.5 \mathrm{~cm}$ substrates and cleaned with ethanol (99.5\%) and subsequently rinsed with acetone $(99.8 \%)$ before use.

\subsection{Instrumentation}

Photocurrent measurements were recorded on a PG 310 potentiostat (HEKA, Germany) in a three electrode configured photo electrochemical cell (PEC) using an Abet Solar simulator (Solar Simulator, Abet Technologies, Milford, CT, USA) as artificial light source. The artificial solar light was calibrated against a silicon solar cell (Newport) to 1.5 equivalent of air mass (AM 1.5). The PEC, a homemade Teflon block with integrated quartz window, was filled with a $0.1 \mathrm{M}$ phosphate buffered saline (PBS) electrolyte solution $(\mathrm{pH} 7.4)$ and the plasma-polymerized films deposited on conducting substrates (fluorinated tin oxide, FTO, or $100 \mathrm{~nm}$ Gold on microscope slides) acted as working electrodes (WE). A platinum rod was used as counter electrode (CE); all recorded current densities were referred to $\mathrm{Ag} / \mathrm{AgCl}(3 \mathrm{M}$ $\mathrm{KCl}$ ). The working electrodes were illuminated with light intensity of $100 \mathrm{~mW} / \mathrm{cm}^{2}$ for $12 \mathrm{~s}$ dark and $12 \mathrm{~s}$ light intervals at their open circuit potentials (OCP).

ToF-SIMS measurements were performed with a PHI TRIFT V nanoTOF instrument (PHI Electronics Ltd, USA). A $30 \mathrm{keV}$, pulsed primary ${ }^{197} \mathrm{Au}^{+}$ion beam was used to sputter and ionize species from each sample surface. PHI's patented dual beam charge neutralization system using a combination of low energy argon ions (up to $10 \mathrm{eV}$ ) and electrons (up to 25 eV) was employed to provide charge neutralization. Positive mass axis calibration was done with $\mathrm{CH}_{3}{ }^{+}, \mathrm{C}_{2} \mathrm{H}_{5}{ }^{+}$and $\mathrm{C}_{3} \mathrm{H}_{7}{ }^{+}$. Spectra were acquired in the bunched mode for 60 seconds from an area of $100 \mu \mathrm{m} \times 100 \mu \mathrm{m}$. The corresponding total primary ion dose was less than $1 \times 10^{12}$ ions $\mathrm{cm}^{-2}$, and thus met the static SIMS regime [34]. A mass resolution $\mathrm{m} / \Delta \mathrm{m}$ of $>7000$ at nominal $\mathrm{m} / \mathrm{z}=27 \mathrm{amu}\left(\mathrm{C}_{2} \mathrm{H}_{3}{ }^{+}\right)$was typically achieved.

Some samples were characterized by multiple recording of positive ion mass spectra, which were collected from sample areas that did not overlap. All recognisable, clear (i.e. unobscured by overlaps) fragment ions from 2 up to $175 \mathrm{amu}$ were used in calculations. The 
peaks were normalized to the total intensity of all selected peaks. Multiple mass spectra were processed with the aid of principal component analysis, PCA [35]. PCA was performed using PLS_Toolbox version 3.0 (Eigenvector Research, Inc., Manson, WA) along with MATLAB software v. 6.5 (MathWorks Inc., Natick, MA).

X-ray photoelectron spectroscopy was performed with a Kratos AXIS Ultra DLD spectrometer, using monochromatic $\mathrm{AlK}_{\alpha}$ radiation $(h v=1486.7 \mathrm{eV})$. The system is equipped with a magnetically confined charge compensation system (low energy electrons are confined and transported to the sample surface by magnetic field). Spectra were recorded using an acceleration voltage of $15 \mathrm{keV}$ at a power of $225 \mathrm{~W}$. Survey spectra were collected with a pass energy of $160 \mathrm{eV}$ and an analysis area of $300 \times 700 \mu \mathrm{m}$. High-resolution spectra were obtained using a $20 \mathrm{eV}$ pass energy and an analysis area of $\sim 300 \times 700 \mu \mathrm{m}$. Data analysis was performed with CasaXPS software (Casa Software Ltd). All binding energies were referenced to the "neutral" C 1s peak at $285.0 \mathrm{eV}$. Core level envelopes were curve-fitted with the minimum number of mixed Gaussian-Lorentzian component profiles. The Gaussian-Lorentzian mixing ratio (typically 30\% Lorentzian and 70\% Gaussian functions); the full width at half maximum, and the positions and intensities of peaks were left unconstrained to result in a best fit.

The polyaniline coating thicknesses were determined by coating silicon wafers with aniline plasma polymer films in parallel with $\mathrm{Au} / \mathrm{Ti} / \mathrm{glass}$ slides. The measurements were accomplished by using a variable-angle spectroscopic ellipsometer (VASE, J.A. Woolam Co. Inc. NE, USA). Scans over the wavelength region $400-800 \mathrm{~nm}$ were performed at three incident angles, viz., $65^{\circ}, 70^{\circ}$ and $75^{\circ}$. The thicknesses of the transparent plasma polymer films were calculated by applying a Cauchy model (silicon + one Cauchy overlayer) using the WVASE32 software (J. A. Woollam Co., Inc., USA). 


\subsection{Synthesis of plasma polymer films}

The experimental set-up for the preparation of RF plasma polymerized aniline thin films has been described elsewhere $[36,37]$. In brief, the reactor chamber was defined by a Pyrex glass cylinder with a height of $35 \mathrm{~cm}$ and a diameter of $17 \mathrm{~cm}$. It comprised an upper, U-shaped brass electrode and a lower electrode that was a copper disc of $10 \mathrm{~cm}$ diameter. The distance between the electrodes was $12.5 \mathrm{~cm}$. The upper electrode was powered by a commercial RF generator (Advanced Energy, RFX 600) connected to a manually operated matching network box to minimize the reflected power. Samples were placed on the lower, grounded electrode. The monomer aniline was placed in a round-bottom flask and connected to the reactor chamber by a stainless steel line via a flow control needle valve. The pumping system consisted of a rotary pump connected to the reactor via a LN2 cold trap and an isolation valve. A base pressure lower than $2 \times 10^{-2}$ Torr was achieved in the reactor prior to adding process vapor. The pressure of the monomer vapor prior to initiation of the glow discharge was set at 0.2 Torr. Plasma-deposited polyaniline thin films were synthesized via both continuous and pulsed plasma power settings. The duty cycle during pulsed mode was 1 $\mathrm{ms} / 20 \mathrm{~ms}$. Peak power (P) was varied between 20, 40 and 60W. Deposition times in the pulsed and continuous modes were 40 and 5 min respectively. The plasma apparatus was placed in a thermostatically controlled laminar flowhood and kept at a temperature of 25-27 ${ }^{\circ} \mathrm{C}$ to maintain a constant pressure and flow of the monomer at 0.2 Torr.

\section{Results and discussion}

\subsection{Preparation of PECVD polyaniline}

PECVD has the advantage over conventional chemical vapor deposition (CVD) methods that it generates reactive species (radicals and ions) in the gas phase at low temperatures, thus allowing the deposition of thin films onto temperature-sensitive substrates [38], such as semiconductors for photovoltaics. In principle, increased temperatures also affect the quality 
of the deposited film itself, which can result in poor adhesion properties or inhomogeneous surface topology of films. Here we conducted a systematic study on the photo-physical properties of plasma-polymerized polyaniline (PAni-pp) by modifying the deposition mode, film thickness, and time of light exposure to achieve the highest effect of photo-doping. Good control over reproducible deposition of polyaniline thin films was essential and was achieved with a reactor base pressure of 20 mTorr and a monomer temperature of $25-27{ }^{\circ} \mathrm{C}$. We also explored plasma deposition of aniline with the entire plasma system heated to $40{ }^{\circ} \mathrm{C}$ inside a flowhood, but this did not result in marked improvements.

\subsubsection{Plasma deposition mode}

The plasma polymerization of the monomer aniline was found to be highly dependent on the experimental parameters. It is well known that physical and chemical processes in the plasma gas phase can result in extensive fragmentation of the monomer molecule, thus yielding films with scrambled chemical structures that are quite different to conventional polymers from the same monomer [23]. Pulsed plasma polymerization often results in marked improvements of retention of monomer structural elements in the film, since in the "on" period the plasma activates radical reactions, which then proceed in a conventional addition mode during the “off" time. One of the objectives of this study was to optimize plasma polymerization process parameters such as duty cycle to achieve maximum retention of the monomer moieties in PAni-pp coatings, since this would be expected to enhance conductivity. In a preliminary study it was established that good control over reproducible film thicknesses was achieved at a plasma power of $20 \mathrm{~W}$. Application of higher powers (40 and $60 \mathrm{~W}$ ) resulted in the deposition of thicker films but with lesser control of thicknesses. The effect of duty cycle was therefore investigated by applying constant wave $(\mathrm{cw})$ and pulsed $(\mathrm{DC}=1 \mathrm{~ms} / 20 \mathrm{~ms})$ modes at $20 \mathrm{~W}$ plasma power. The surface chemistry of the resultant polyaniline plasma polymer (PAni-pp) coatings was studied using ToF-SIMS. 

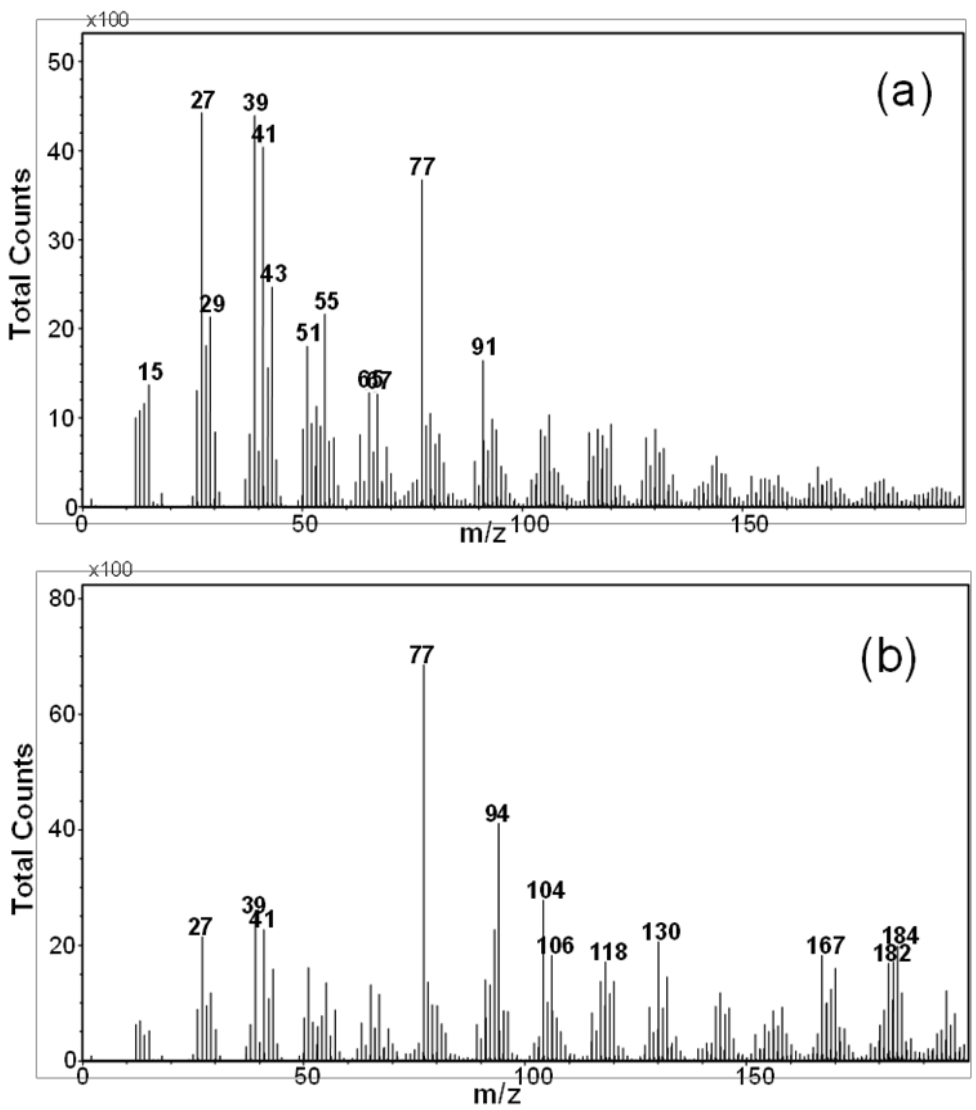

Figure 2: Positive ion static mass spectra recorded with PAni-pp films generated using: (a) continuous plasma and (b) pulsed plasma, both at plasma power input of $20 \mathrm{~W}$.

Figure 2 shows positively charged ions, wide range (0-200 amu) static mass spectra for PAni-pp films that were produced using cw (trace a) and pulsed (trace b) plasmas. The spectra were complex and they showed distinct differences, attesting to substantial compositional differences upon using different plasma conditions. Both spectra contain a peak at $\mathrm{m} / \mathrm{z}=77 \mathrm{amu}$, which can be assigned to the $\mathrm{C}_{6} \mathrm{H}_{5}{ }^{+}$fragment ion, a fingerprint ion originating from aniline in ToF-SIMS. This is the major fragment in the spectrum for the PAni-pp film obtained using pulsed mode, whilst the spectrum for the constant wave plasma surface is obscured by multiple low molecular weight fragment ions, mostly assignable to hydrocarbon species. 
Direct comparison of polyaniline coatings is difficult as the spectral differences are not related to unique peaks but to changes in relative intensities of common peaks. The univariate comparison could be ambiguous, thus we used multivariate principal component analysis (PCA) to aid in the interpretation of the static positive ToF-SIMS spectra. Figure 3a shows the scores plot on PC1 and PC2 for the positive mass spectra of Figure 2. The spectra form two well-separated clusters along PC1, which retains almost $99 \%$ of the original data variance, making it unnecessary to consider PC2 for further analysis. The specimens are clearly different, but their surfaces are quite uniform/homogeneous, as indicated by the low scatter of the experimental points in each group.

Figure $3 \mathrm{~b}$ displays loadings of positive fragment ions on $\mathrm{PC} 1$, which explain the causes of observed differences between the samples. The surface of the PAni-pp film prepared with constant wave plasma mode is characterized by positively loaded hydrocarbon fragment ions like $\mathrm{CH}_{3}{ }^{+}, \mathrm{C}_{2} \mathrm{H}_{3}{ }^{+}, \mathrm{C}_{3} \mathrm{H}_{3}{ }^{+}, \mathrm{C}_{3} \mathrm{H}_{5}{ }^{+}$and also by an aromatic $\mathrm{C}_{7} \mathrm{H}_{7}{ }^{+}$tropylium ion. The surface of PAni-pp films prepared using pulsed plasma, on the other hand, is dominated by fragment ions including $\mathrm{C}_{6} \mathrm{H}_{5}^{+}, \mathrm{C}_{6} \mathrm{H}_{8} \mathrm{~N}^{+}, \mathrm{C}_{6} \mathrm{H}_{4} \mathrm{~N}_{2}{ }^{+}, \mathrm{C}_{12} \mathrm{H}_{12} \mathrm{~N}^{+}$and $\mathrm{C}_{12} \mathrm{H}_{11} \mathrm{~N}_{2}{ }^{+}$that are indicative of polyaniline. The latter two reflect the presence of aniline dimers. Clearly, under continuous plasma excitation, there is significant loss of amine groups from aniline in the plasma and the resultant film has a higher extent of hydrocarbon character. Thus, pulsed plasma conditions appear to be essential for the optimization of polyaniline-like composition in plasma-deposited polyaniline films. Low power continuous plasmas, such as the $20 \mathrm{~W}$ used in this study, have often been used to attempt to reduce monomer fragmentation; for example Cruz et al [31] and Gong et al [32] showed that plasma conditions affected the composition of aniline plasma polymers but did not investigate pulsing. Pulsing in aniline plasma deposition was used by Ameen et al [33], but they also used higher power (120W) and did not compare pulsing with continuous plasma operation. 

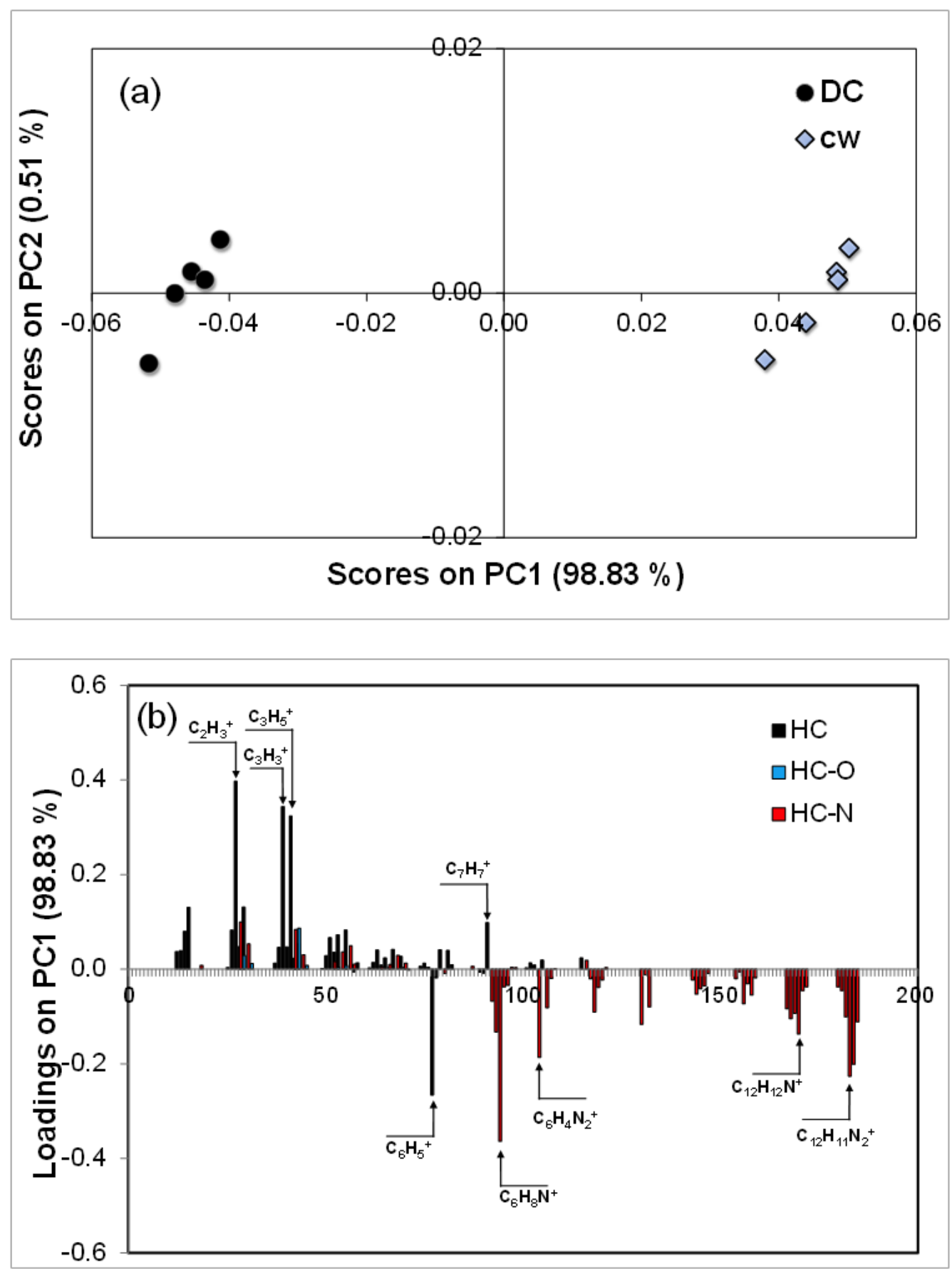

Figure 3: PCA of positive ion static mass spectra for PAni-pp films generated using continuous plasma (cw) and pulsed plasma (DC) at power of $20 \mathrm{~W}$ : (a) scores plot on PC1 and PC2; (b) loadings of positive fragment ions on PC1.

As the ToF-SIMS results indicate that the application of pulsed plasma resulted in higher retention of the monomer structure and thus in less scrambled, more polyaniline-like 
coatings, PAni-pp films for the photophysical investigations were generated using pulsed 20 W power plasma.

\subsection{Photo-doping of polyaniline}

The effect of photo-induced "self-doping" - or photo-doping - has never been reported with PAni-pp films. It can be understood as a light-induced transformation from a less oxidized form of polyaniline to another form with a higher grade of oxidation.

In our initial studies, transparent PAni-pp films were deposited onto a FTO substrate and observed to possess grain type surface topology with irregular sizes by Scanning Electron Microscopy (SEM, Fig. 4a). Initial photophysical investigations of the Pani-pp films revealed that the films responded with increased negative current densities the more they were exposed to artificial sunlight. Although the FTO substrate itself was intrinsically an electron donating layer (n-type, Fig. 4b), the photocurrent experiments on the plasma films showed a faint $p$-type photocurrent response indicating that PAni-pp is a photoactive material. In the course of the chronoamperometric experiments it was noticed that the p-type photocurrent behaviour (electron acceptor) became more pronounced when the films were illuminated for longer periods of times. After 30 min total illumination the photocurrent density increased by a factor of 10 (blue, Figure 4c) at the open-circuit potential (OCP). 

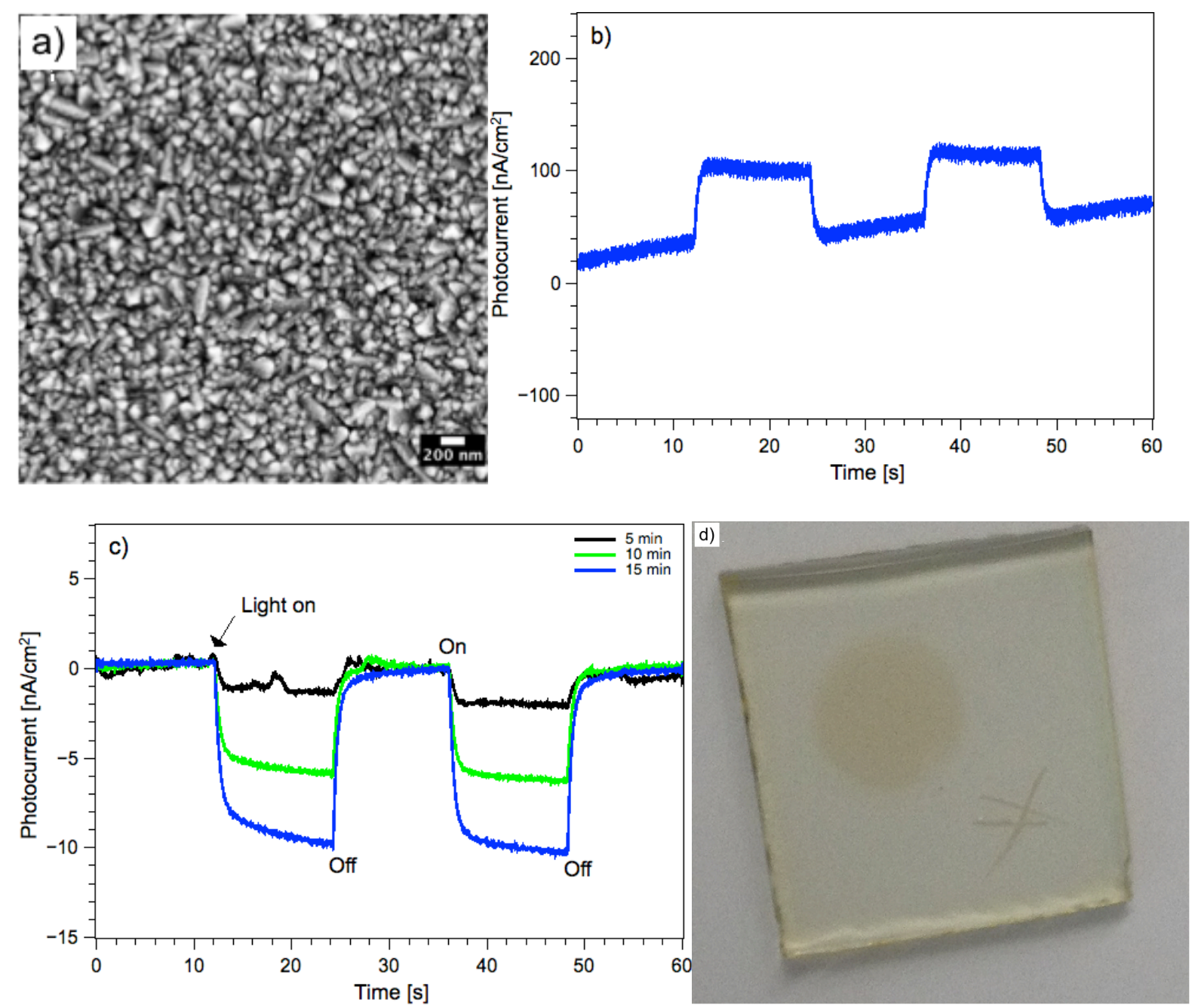

Figure 4: a) SEM image of $160 \mathrm{~nm}$ PAni-pp deposited onto a FTO substrate via pulsed plasma technique; b) chronoamperogram of the bare FTO substrate showing FTO as intrinsically n-type material; c) chronoamperograms of the same PAni-pp film showing increasing $p$-type photocurrent responses within increasing times $(5,10$ and $15 \mathrm{~min})$ of light exposure under 1.5 AM artificial solar light. The photocurrent densities were recorded repetitively under dark and $1.5 \mathrm{AM}\left(100 \mathrm{~mW} / \mathrm{cm}^{2}\right)$ solar light for $12 \mathrm{~s}$ intervals, where the first, third and fifth 12 seconds record the dark current. All photocurrent responses were recorded at their open-circuit potentials (OCP); d) photographic picture of the PAni-pp film showing a "dark stain" caused by irradiation with light.

Obviously, artificial sunlight enhanced the photophysical properties of the PAni-pp film as a p-type semiconductor, causing doping effects in the thin polyaniline film, where 
light plays the major role in doping (photo-doping). The photo-doping of the PAni-pp film triggered by sunlight was underpinned by the fact that it could be observed with the naked eye. The area of the initially semi-transparent Pani-pp film that was exposed to light during chronoamperometric measurements underwent a visible change in color (dark stain), as shown in Figure 4d. X-ray photoelectron spectroscopy (XPS) was used to unravel the effect of photo-induced doping on plasma polymerized polyaniline films and it was also investigated whether the film thickness plays a role.

\subsubsection{Film thickness}

The vapour pressure of aniline is low compared to conventional monomers used in plasma polymerization. Consequently, when plasma is initiated the base pressure decreases, which is indicative of monomer consumption. Since the pulsed plasma technique allowed good control over the monomer consumption (see experimental details), the film thickness could be controlled by adjusting the deposition time. PAni-pp films with thicknesses of $25 \mathrm{~nm}, 40 \mathrm{~nm}$, $80 \mathrm{~nm}$ and 160-200 $\mathrm{nm}$ were produced. Since FTO behaved as an intrinsically n-type substrate, all films were deposited onto a $100 \mathrm{~nm}$ gold layer (above $40 \mathrm{~nm}$ Ti on microscope slide), as a p-type material due to its photoelectric effect. All films were exposed to artificial solar light for 5 minutes before chronoamperometric measurements were undertaken. Figure 5a shows the photocurrent responses upon illumination with artificial solar light (AM 1.5). The thinner films with 25 and $40 \mathrm{~nm}$ thicknesses responded with higher current densities, where the highest photocurrent responses were achieved with $-540 \mathrm{nA} / \mathrm{cm}^{2}$ with the $40 \mathrm{~nm}$ PAni-pp layer. The thicker layers of PAni-pp, however, responded with lower current densities, well below $-100 \mathrm{nA} / \mathrm{cm}^{2}$, suggesting that limiting penetration depth of light and increasing ohmic resistance with increasing film thicknesses were causing a drop of electron mobility that resulted in poorer photocurrent responses. The ideal film thickness was found to be $25-40 \mathrm{~nm}$ to obtain a high-performing organic semiconductor based on plasma polymerized polyaniline films. 

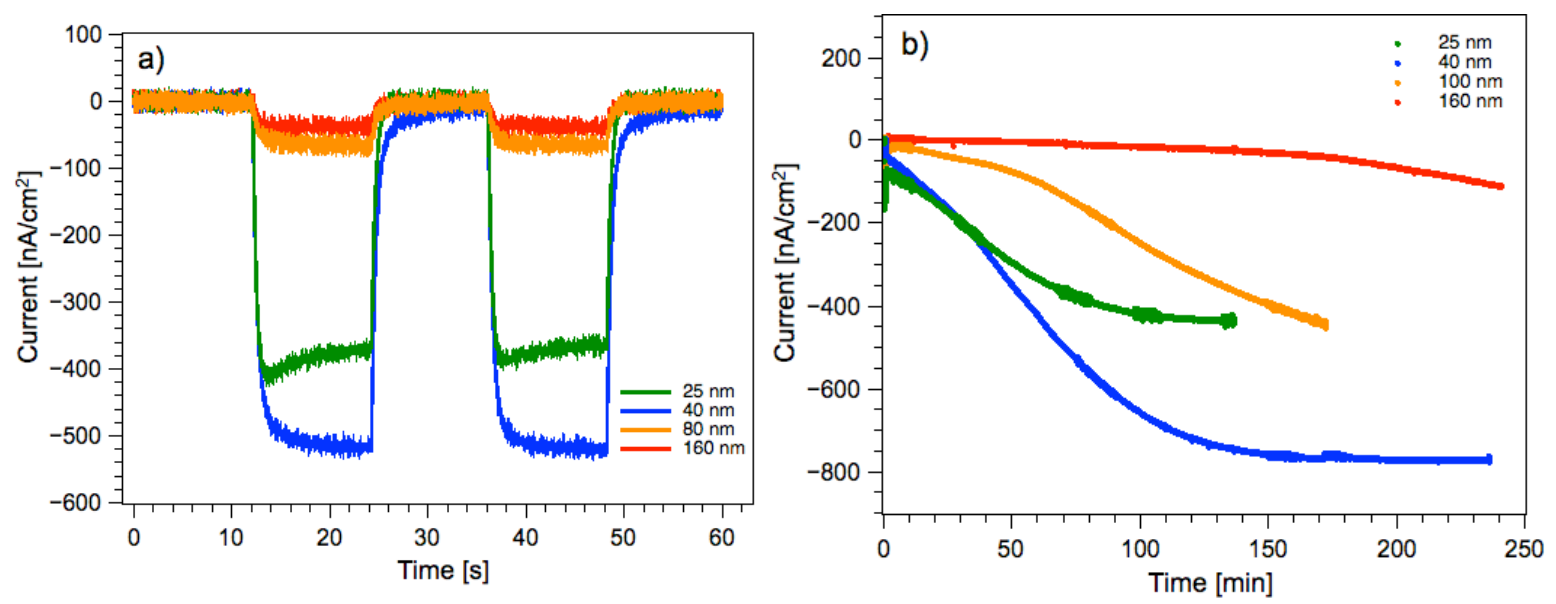

Figure 5: a) Chronoamperograms of four different PAni-pp films with 25, 40, 80 and $160 \mathrm{~nm}$ thickness. The photocurrent densities were recorded repetitively under dark and 1.5 AM (100 $\mathrm{mW} / \mathrm{cm}^{2}$ ) solar light in 12 second intervals, where the first, third and fifth 12 seconds record the dark currents. All photocurrent responses were recorded at their open-circuit potentials (OCP) vs $\mathrm{Ag} / \mathrm{AgCl}(3 \mathrm{M} \mathrm{KCl})$; b) Photocurrent responses of four different PAni-pp films with $25,40,100$ and $160 \mathrm{~nm}$ thicknesses under continuous exposure to $100 \mathrm{~mW} / \mathrm{cm}^{2}$ (1.5 AM) for up to 4 hours; the current densities were recorded at their OCP against $\mathrm{Ag} / \mathrm{AgCl}(3 \mathrm{M} \mathrm{KCl})$ in $0.1 \mathrm{M}$ PBS solution.

\subsubsection{Long-term exposure of PAni-pp to solar light}

The photo-induced doping of PAni-pp was initiated once the film was exposed to $1.5 \mathrm{AM}$ artificial solar light, resulting in an organic semiconductor with p-type behaviour. As a consequence of these observations, we conducted long-term exposure experiments of PAnipp with four different film thicknesses for up to four hours. The PAni-pp films were deposited on gold substrates and their thicknesses were ellipsometrically determined to be 25 , 40, 100 and $160 \mathrm{~nm}$. Figure $5 \mathrm{~b}$ shows the chronoamperograms of selected films under continuous irradiation. Again, the thicker films, 160 and $100 \mathrm{~nm}$, responded with lower current densities under continuous exposure to light whilst the $100 \mathrm{~nm}$ film showed notable 
current responses of more than $-400 \mathrm{nA} / \mathrm{cm}^{2}$ after 2.5 hours. Note, that the steady state was still not achieved, suggesting that longer times of light exposure are needed. In contrast, steady state was already achieved after $100 \mathrm{~min}$ with the $25 \mathrm{~nm}$ film, resulting in similar photocurrent densities. The highest photocurrent responses were obtained from $40 \mathrm{~nm}$ films, with highest current densities of $-800 \mathrm{nA} / \mathrm{cm}^{2}$ after $2.5 \mathrm{~h}$. Again, the $40 \mathrm{~nm}$ PAni-pp film showed the best performance among the series showing no significant loss after $4 \mathrm{~h}$ in total. Hence, all PAni-pp films subjected to further analysis were produced with $40 \mathrm{~nm}$ thicknesses.

\subsubsection{X-ray photoelectron spectroscopy analysis}

To understand the photo-induced doping effect of PAni-pp films on a molecular level, $40 \mathrm{~nm}$ PAni-pp films were deposited onto $\mathrm{Au} / \mathrm{Ti} /$ glass and subjected to surface analysis by XPS. The untreated sample and its homologues after exposure to 1.5 AM artificial sunlight in the photoelectrochemical cell for $5 \mathrm{~min}$ and $3 \mathrm{~h}$ were examined. The survey spectra before and after illumination revealed differences in elemental compositions, as summarized in Table 1.

Table 1: XPS elemental composition for $40 \mathrm{~nm}$ PAni-pp film on $\mathrm{Au} / \mathrm{Ti} / \mathrm{glass}$ slide prior to and after 5 and 180 min of irradiation with $1.5 \mathrm{AM}$ artificial sunlight, respectively.

\begin{tabular}{|l|l|l|l|}
\hline \multirow{2}{*}{ Irradiation time, $\min$} & \multicolumn{2}{|l|}{ Composition, at.\% } & \multicolumn{2}{|l|}{} \\
\cline { 2 - 4 } & $\mathrm{O}$ & $\mathrm{N}$ & 86.4 \\
\hline 0 & 3.5 & 10.1 & 83.3 \\
\hline $5^{*}$ & 7.1 & 8.6 & 80.4 \\
\hline $180^{*}$ & 10.9 & 8.1 & \\
\hline
\end{tabular}

* $5 \mathrm{~min}$ and $180 \mathrm{~min}$ irradiated specimens showed also presence of 1.0 at $\%$ of Si and 0.5 at. $\%$ of Au respectively

The control sample showed 3.5 at.\% of oxygen, which doubled upon the first 5 mins of irradiation. Prolonged exposure to artificial sunlight resulted in a further increase in the 
oxygen content, which reached a value of 11.0 at.\% after $3 \mathrm{~h}$. The XPS results thus revealed oxygen incorporation into the PAni-pp coating upon irradiation. The rate of the reaction changed with time. The initial irradiation period resulted in fast initial oxidation, whose rate dropped distinctly, likely exponentially, with time. Figure 6 shows high resolution C1s core level spectra prior to (trace a) and after 3 hours of illumination (trace b).
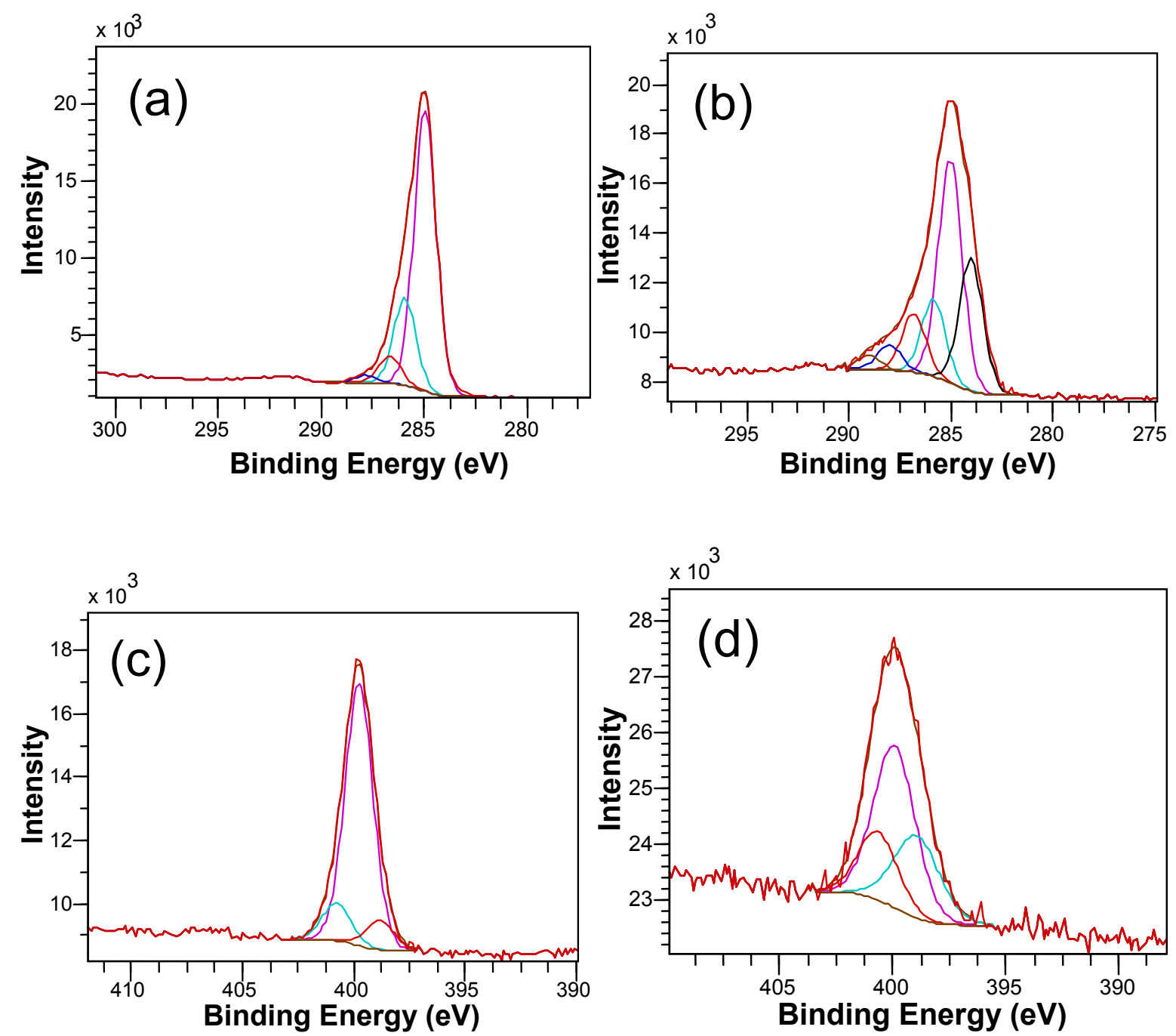

Figure 6: High resolution component fitted C1s and N1s core level spectra for $40 \mathrm{~nm}$ PAnipp film on $\mathrm{Au} / \mathrm{Ti} /$ glass slide: (a) $\mathrm{C} 1 \mathrm{~s}$ for untreated coating; (b) $\mathrm{C} 1 \mathrm{~s}$ for coating irradiated for $3 \mathrm{~h}$ with 1.5 AM artificial sunlight; (c) N1s for untreated coating; (d) N1s for coating irradiated for $3 \mathrm{~h}$ with $1.5 \mathrm{AM}$ artificial sunlight. 
The assignments of the fitted components and the compositions of the C1s levels are summarized in Table 2. The untreated PAni-pp control consisted of four types of carbon environments. The $\mathrm{CC} / \mathrm{CH}\left(\mathrm{sp}^{3}\right)$ and $\mathrm{C}-\mathrm{N}$ components accounted for 69.5 and $21.8 \%$ of the total $\mathrm{C} 1 \mathrm{~s}$ envelope respectively. The values diverged from the theoretical stoichiometry of polyaniline due to the complexity of propagating species present in a gas discharge during plasma polymerization. The presence of $\mathrm{C}-\mathrm{O}$ and $\mathrm{C}=\mathrm{O}$ components, at 6.9 and $1.9 \%$ respectively, indicates that the surface was lightly oxidized during the plasma coating fabrication and (or) after that, upon exposure to air, as has been observed for other amine plasma-deposited coatings [39-41].

After three hours of illumination the chemical composition of PAni-pp had changed. The $\mathrm{C} 1 \mathrm{~s}$ spectrum showed 6 components which were assigned (Table 2) to $\mathrm{C}=\mathrm{C}\left(\mathrm{sp}^{2}\right)$, $\mathrm{C}$ $\mathrm{C} / \mathrm{C}-\mathrm{H}, \mathrm{C}-\mathrm{N}, \mathrm{C}=\mathrm{O}$ and $\mathrm{COO}$ environments. The appearance of a peak at $284.0 \mathrm{eV}$, which corresponded to an unsaturated carbon environment $\left(\mathrm{sp}^{2}\right)$, was likely to be primarily responsible for the PAni-pp coating conductivity.

Table 2. Compositions of C1s and N1s core level spectra for untreated $40 \mathrm{~nm}$ PAni-pp film on $\mathrm{Au} / \mathrm{Ti} / \mathrm{glass}$ slide and after its irradiation with $1.5 \mathrm{AM}$ artificial sunlight for $180 \mathrm{~min}$.

\begin{tabular}{|c|c|c|c|c|c|c|c|c|c|}
\hline \multirow{3}{*}{$\begin{array}{l}\text { Irradiation } \\
\text { time, min }\end{array}$} & \multicolumn{9}{|c|}{ Composition, $\%$ of total } \\
\hline & \multicolumn{6}{|l|}{$\mathrm{C} 1 \mathrm{~s}$} & \multicolumn{3}{|l|}{ N1s } \\
\hline & $\begin{array}{l}C=C \\
284.0\end{array}$ & $\begin{array}{l}\text { C-C/C-H } \\
285.0\end{array}$ & $\begin{array}{l}\text { C-N } \\
286.0\end{array}$ & $\begin{array}{l}\mathrm{C}-\mathrm{O} \\
286.6\end{array}$ & $\begin{array}{l}\mathrm{C}=\mathrm{O} \\
288.0\end{array}$ & $\begin{array}{l}\mathrm{O}-\mathrm{C}=\mathrm{O} \\
289.0\end{array}$ & $\begin{array}{l}-\mathrm{N}= \\
398.8\end{array}$ & $\begin{array}{l}\text {-NH- } \\
399.8\end{array}$ & $\begin{array}{l}-\mathrm{HN}^{+} \\
400.8\end{array}$ \\
\hline 0 & 0 & 69.5 & 21.8 & 6.9 & 1.9 & 0 & 9.0 & 79.5 & 11.5 \\
\hline 180 & 24.9 & 41.9 & 14.5 & 11.1 & 4.9 & 2.6 & 28.2 & 51.2 & 20.6 \\
\hline
\end{tabular}


Since nitrogen plays the key role in PAni structures, being the bridging atom in the polymer chain and the redox mediator between polymer units, the N1s core level spectra are of particular value. Figure $6 \mathrm{c}$ shows that prior to illumination, nitrogen was mainly present in the form of amine bonds (79.5\% in Table 2$)$ with small amounts of imine and amine polaron components. The composition of the N1s spectrum reflects the insulating benzenoid/aromatic character of the PAni-pp coating [42-45]. It appears that prior to illumination the PAni-pp film mainly comprised a structure similar to leucoemeraldine base with admixtures of the emeraldine base (Fig. 1). After 3 hours of irradiation the insulating amine bond had decreased by $\sim 30 \%$ and that phenomenon was accompanied by increased formation of imine and amine polarons. An increase in amine polarons content from 11.5 to $20.6 \%$ implies a more conductive polymer. A sharp increase in the amount of imine present reinforced the idea that unsaturation led to higher conductivity, meaning the irradiated Pani-pp films could be classed as alike to a pernigraniline base.

\subsection{Doping PECVD polyaniline with metal centres}

Binding of various metals into the polymeric matrix was achieved through incubating the thin films with a $0.01 \mathrm{M}$ solution of the respective solutions of $\mathrm{Mn}\left(\mathrm{NO}_{3}\right)_{2}, \mathrm{Co}\left(\mathrm{NO}_{3}\right)_{2}, \mathrm{CuSO}_{4}$ and $\mathrm{CuCl}_{2}$ for three days. These metals were chosen as they display interesting redox chemistry, which potentially can be exploited for catalytic activity. These metals are cheap and abundant and are known to have a high affinity for nitrogen-containing ligands. The solutions were kept in the dark for the duration of binding. Enhanced photocurrents were observed with all samples, as shown in Fig. 7. The highest photocurrent response results from $\mathrm{CuCl}_{2}$ doping, with a current density more than $-3 \mu \mathrm{A} / \mathrm{cm}^{2}$, which is almost double that of its sulfate analogue. The nitrate salts of $\mathrm{Co}(\mathrm{II})$ and $\mathrm{Mn}(\mathrm{II})$ both showed a photocurrent response at -1 $\mathrm{mA} / \mathrm{cm}^{2}$. 


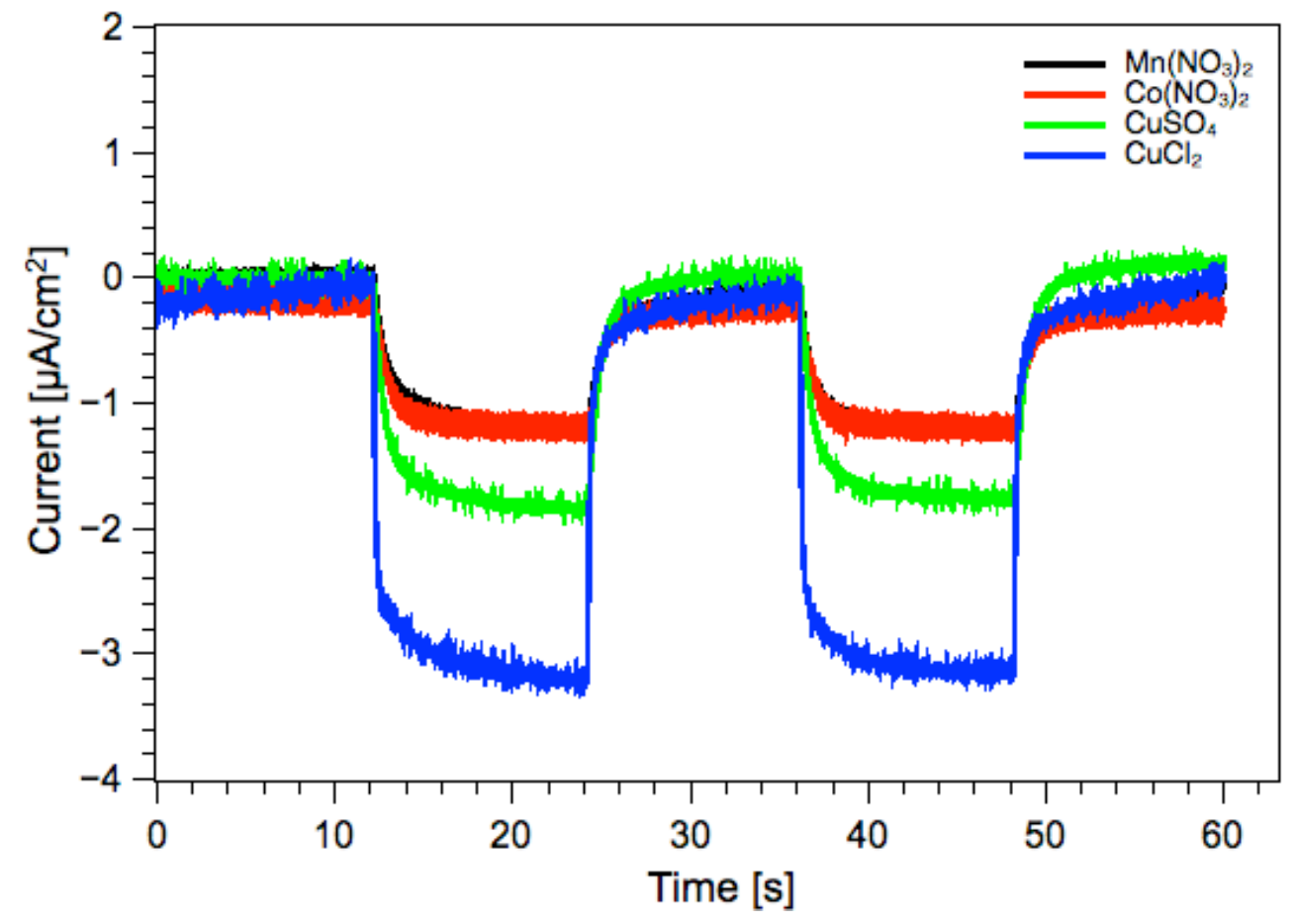

Figure 7: Chronoamperograms of four different 40-45 nm PAni-pp samples decorated with $0.01 \mathrm{M}$ aqueous solution of $\mathrm{Mn}\left(\mathrm{NO}_{3}\right)_{2}, \mathrm{Co}\left(\mathrm{NO}_{3}\right)_{2}, \mathrm{CuSO}_{4}$ and $\mathrm{CuCl}_{2}$ for 3 days. The photocurrent responses were recorded at their OCP in $0.1 \mathrm{M}$ phosphate buffered saline solution in a three-electrode configured electrochemical cells using PAni/M substrate as working electrode, a Pt rod as counter electrode and $\mathrm{Ag} / \mathrm{AgCl}(3 \mathrm{M} \mathrm{KCl})$ as reference electrode. The first, third and fifth $12 \mathrm{~s}$ record the dark current.

All of the transition metal centres used in this study have different stable oxidation states (for example, cobalt is relatively stable in the oxidation states II and III). A possible explanation for the increase in photocurrent density is photo-activated electron transfer from the metal centres to the polyaniline backbone. Also, the metals centres could act as relays for electrons "hopping" between polyaniline fragments, thus increasing the overall conductivity and photocurrent density. Most likely, a combination of these two effects is the reason for the observed effect. 
Table 3: Ellipsometry data showing the effect of illumination on PAni film thickness.

\begin{tabular}{l|c|c} 
Treatment & Substrate & $\begin{array}{c}\text { Average } \\
\text { thickness }(\mathbf{n m})\end{array}$ \\
\hline Control & Silicon & 40.8 \\
Sample 1 - untreated & Gold & 44.9 \\
Sample 1 - 5 Mins & Gold & 40.5 \\
Sample 2 - untreated & Gold & 43.5 \\
Sample 2 - 3 Hours & Gold & 16.9
\end{tabular}

Ellipsometry results (Table 3) showed that the films degraded with time. Film thicknesses changed and delamination occurred. While photo-oxidation increased the conductivity of the films as discussed above, it resulted in degradation of the polyaniline when doped with transition metal centres. Further study is needed to investigate how this might be overcome or a suitable compromise in performance achieved.

\section{Conclusions}

We successfully plasma polymerized polyaniline (PAni-pp) films with high structural retention when pulsing was used for the plasma excitation,and explored the thin films as potential candidates as organic semiconductor with p-type properties (electron acceptor). Chronoamperometric investigations revealed that these films increase their performances as photoactive semiconductor when irradiated with artificial sunlight (photo-doping or photoinduced doping). Analysis by XPS prior to illumination and after long-term exposure to one equivalent of sunlight allowed us to understand the photo-doping effect as light-triggered transformation from a reduced form of polyaniline to another form with higher grades of 
oxidation. These unique properties of thin PAni-pp films becoming active just by switching on light offers promise for applications in sensor, photocatalysis, or optoeletronic materials where light plays a crucial role. Usually, chemical modification or harsh chemical conditions such as strong acids and oxidants are required to dope polyaniline films. Here, exposure to light suffices to achieve the film doping by itself, which has never been described before.

After doping the PECVD polyaniline with various transition metals, the films displayed an enhanced photocurrent response; however, the long-term stability of films was drastically decreased. Transition metal doped PECVD polyaniline would have huge potential as an inexpensive and efficient photocatalytic materials for many applications, if a solution to increase the long-term stability can be found in future research.

\section{References}

[1] T.P. Yoon, M.A. Ischay, J. Du, Visible light photocatalysis as a greener approach to photochemical synthesis, Nat. Chem. 2 (2010) 527-532. doi:10.1038/NCHEM.687.

[2] L. Schmidt-Mende, A. Fechtenkotter, K. Mullen, E. Moons, R.H. Friend, J.D. MacKenzie, Self-organized discotic liquid crystals for high-efficiency organic photovoltaics, Science. 293 (2001) 1119-1122. doi:10.1126/science.293.5532.1119.

[3] J. Yan, T. Wei, B. Shao, Z. Fan, W. Qian, M. Zhang, et al., Preparation of a graphene nanosheet/polyaniline composite with high specific capacitance, Carbon. 48 (2010) 487-493. doi:10.1016/j.carbon.2009.09.066.

[4] E. Song, J.-W. Choi, Conducting Polyaniline Nanowire and Its Applications in Chemiresistive Sensing, Nanomaterials. 3 (2013) 498.

[5] W.-T. Sun, Y. Yu, H.-Y. Pan, X.-F. Gao, Q. Chen, L.-M. Peng, CdS quantum dots sensitized TiO2 nanotube-array photoelectrodes, J. Am. Chem. Soc. 130 (2008) 1124-+. doi:10.1021/ja0777741. 
[6] S. Chandrasekaran, T.J. Macdonald, Y.J. Mange, N.H. Voelcker, T. Nann, A quantum dot sensitized catalytic porous silicon photocathode, J. Mater. Chem. A. 2 (2014) 9478-9481. doi:10.1039/c4ta01677g.

[7] T.J. Macdonald, J. Xu, S. Elmas, Y.J. Mange, W.M. Skinner, H. Xu, et al., NiO Nanofibers as a Candidate for a Nanophotocathode, Nanomaterials. 4 (2014) 256-266. doi:10.3390/nano4020256.

[8] D.P. Tran, T.J. Macdonald, B. Wolfrum, R. Stockmann, T. Nann, A. Offenhaeusser, et al., Photoresponsive properties of ultrathin silicon nanowires, Appl. Phys. Lett. 105 (2014) 231116. doi:10.1063/1.4904089.

[9] S.E. Shaheen, D.S. Ginley, G.E. Jabbour, Organic-based photovoltaics. toward lowcost power generation, Mrs Bull. 30 (2005) 10-19. doi:10.1557/mrs2005.2.

[10] C.J. Brabec, Organic photovoltaics: technology and market, Sol. Energy Mater. Sol. Cells. 83 (2004) 273-292. doi:10.1016/j.solmat.2004.02.030.

[11] T. Barman, A.R. Pal, J. Chutia, Comparative study of structural and optical properties of pulsed and RF plasma polymerized aniline films, Appl. Surf. Sci. 313 (2014) 286-292. doi:10.1016/j.apsusc.2014.05.205.

[12] Y. Cao, J. Qiu, P. Smith, Effect of solvents and co-solvents on the processibility of polyaniline: I. solubility and conductivity studies, Synth. Met. 69 (1995) 187-190. doi:10.1016/0379-6779(94)02412-R.

[13] R.C. Chatelier, C.J. Drummond, D.Y.C. Chan, Z.R. Vasic, T.R. Gengenbach, H.J. Griesser, Theory of Contact Angles and the Free Energy of Formation of Ionizable Surfaces: Application to Heptylamine Radio-Frequency Plasma-Deposited Films, Langmuir. 11 (1995) 4122-4128. doi:10.1021/la00010a078.

[14] D. Liu, X. Wang, J. Deng, C. Zhou, J. Guo, P. Liu, Crosslinked Carbon Nanotubes/Polyaniline Composites as a Pseudocapacitive Material with High Cycling Stability, Nanomaterials. 5 (2015) 1034. 
[15] D.-W. Wang, F. Li, J. Zhao, W. Ren, Z.-G. Chen, J. Tan, et al., Fabrication of Graphene/Polyaniline Composite Paper via In Situ Anodic Electropolymerization for HighPerformance Flexible Electrode, Acs Nano. 3 (2009) 1745-1752. doi:10.1021/nn900297m.

[16] R.Y. Suckeveriene, G. Mechrez, O.H. Filiba, S. Mosheev, M. Narkis, Synthesis of hybrid polyaniline/carbon nanotubes nanocomposites in toluene by dynamic interfacial inverse emulsion polymerization under sonication, J. Appl. Polym. Sci. 128 (2013) 21292135. doi:10.1002/app.38405.

[17] E.V. Ovsyannikova, M.Y. Grosheva, N.M. Alpatova, Autocatalytic character of anodic polymerization of aniline in water-organic acid solutions, Russ. J. Electrochem. 40 (2004) 1089-1091. doi:10.1023/B:RUEL.0000046496.16092.15.

[18] M.R. Nabid, Z. Zamiraei, R. Sedghi, Water-soluble Aniline/o-Anisidine Copolymer: Enzymatic Synthesis and Characterization, Iran. Polym. J. 19 (2010) 699-706.

[19] F. Koyama, T. Kawai, Photochemical reaction between diphenylamine and 1,1,1tribromoethane and photo-induced pattern formation, Dyes Pigments. 98 (2013) 323-326. doi:10.1016/j.dyepig.2013.03.001.

[20] E.T. Kang, K.G. Neoh, K.L. Tan, Polyaniline: A polymer with many interesting intrinsic redox states, Prog. Polym. Sci. 23 (1998) 277-324. doi:10.1016/S00796700(97)00030-0.

[21] T. Barman, A.R. Pal, Contradictory ageing behaviour and optical property of iodine doped and H2SO4 doped pulsed DC plasma polymerized aniline thin films, Solid State Sci. 24 (2013) 71-78. doi:10.1016/j.solidstatesciences.2013.06.014.

[22] L. Martinu, D. Poitras, Plasma deposition of optical films and coatings: A review, J. Vac. Sci. Technol. Vac. Surf. Films. 18 (2000) 2619. doi:10.1116/1.1314395.

[23] R. D’Agostino, Wiley InterScience (Online service), Advanced plasma technology, Wiley-VCH, Weinheim; Chichester, 2008. http://dx.doi.org/10.1002/9783527622184 (accessed November 10, 2015). 
[24] A. Michelmore, C. Charles, R.W. Boswell, R.D. Short, J.D. Whittle, Defining Plasma Polymerization: New Insight Into What We Should Be Measuring, Acs Appl. Mater. Interfaces. 5 (2013) 5387-5391. doi:10.1021/am401484b.

[25] J.G. Wang, K.G. Neoh, E.T. Kang, Comparative study of chemically synthesized and plasma polymerized pyrrole and thiophene thin films, Thin Solid Films. 446 (2004) 205-217. doi:10.1016/j.tsf.2003.09.074.

[26] A.M. Mathew, P. Predeep, Plasma-polymerized elastomer/conducting polymer composite: Structural and optical characterization, Polym. Compos. 34 (2013) 1091-1098. doi:10.1002/pc.22517.

[27] C.J. Hall, P.J. Murphy, H.J. Griesser, Influence of Tetramethyldisiloxane-Oxygen Mixtures on the Physical Properties of Microwave PECVD Coatings and Subsequent PostPlasma Reactions: Influence of Tetramethyldisiloxane-Oxygen Mixtures on PECVD Coatings, Plasma Process. Polym. 12 (2015) 555-563. doi:10.1002/ppap.201400159.

[28] M.-G. Mureşan, A.C. Campbell, P. Ondračka, V. Buršíková, V. Peřina, T. Polcar, et al., Protective double-layer coatings prepared by plasma enhanced chemical vapor deposition on tool steel, Surf. Coat. Technol. 272 (2015) 229-238. doi:10.1016/j.surfcoat.2015.04.002.

[29] C.J. Hall, P.J. Murphy, T. Schmauder, H.J. Griesser, Variations in graded organosilicone microwave PECVD coatings modify stress and improve the durability on plastic substrates, Surf. Coat. Technol. $259 \quad$ (2014) 616-624. doi:10.1016/j.surfcoat.2014.10.022.

[30] L. Martinu, M.R. Wertheimer, J.E. Klemberg-Sapieha, Recent Advances in Plasma Deposition of Functional Coatings on Polymers, MRS Proc. 544 (1998). doi:10.1557/PROC544-251.

[31] G.. Cruz, J. Morales, M.. Castillo-Ortega, R. Olayo, Synthesis of polyaniline films by plasma polymerization, Synth. Met. 88 (1997) 213-218. doi:10.1016/S0379-6779(97)038538. 
[32] X. Gong, L. Dai, A.W.H. Mau, H.J. Griesser, Plasma-polymerized polyaniline films: Synthesis and characterization, J. Polym. Sci. Part Polym. Chem. 36 (1998) 633-643. doi:10.1002/(SICI)1099-0518(199803)36:4<633::AID-POLA12>3.0.CO;2-N.

[33] S. Ameen, M. Song, D.-G. Kim, Y.-B. Im, H.-K. Seo, Y.S. Kim, et al., Iodine doped polyaniline thin film for heterostructure devices via PECVD technique: Morphological, structural, and electrical properties, Macromol. Res. 20 (2012) 30-36. doi:10.1007/s13233012-0009-2.

[34] D. Briggs, Surface analysis of polymers by XPS and static SIMS, Digitally printed 1st pbk. version, Cambridge University Press, Cambridge; New York, 2005.

[35] M. Jasieniak, D. Graham, P. Kingshott, L. Gamble, H. Griesser, Surface Analysis of Biomaterials, in: J. Rivière, S. Myhra (Eds.), Handb. Surf. Interface Anal., CRC Press, 2009: pp. 529-564. http://www.crcnetbase.com/doi/abs/10.1201/9781420007800-c17 (accessed November 6, 2015).

[36] H.J. Griesser, Small scale reactor for plasma processing of moving substrate web, Vacuum. 39 (1989) 485-488. doi:10.1016/0042-207X(89)90272-8.

[37] A.M. Sandstrom, M. Jasieniak, H.J. Griesser, L. Grøndahl, J.J. Cooper-White, Effects of Varying Heptylamine and Propionaldehyde Plasma Polymerization Parameters on Mesenchymal Stem Cell Attachment, Plasma Process. Polym. 10 (2013) 19-28. doi:10.1002/ppap.201200009.

[38] F. Massines, C. Sarra-Bournet, F. Fanelli, N. Naudé, N. Gherardi, Atmospheric Pressure Low Temperature Direct Plasma Technology: Status and Challenges for Thin Film Deposition, Plasma Process. Polym. 9 (2012) 1041-1073. doi:10.1002/ppap.201200029.

[39] T.R. Gengenbach, R.C. Chatelier, H.J. Griesser, Characterization of the Ageing of Plasma-deposited Polymer Films: Global Analysis of X-ray Photoelectron Spectroscopy Data, Surf. Interface Anal. 24 (1996) 271-281. doi:10.1002/(SICI)10969918(199604)24:4<271::AID-SIA116>3.0.CO;2-J. 
[40] T.R. Gengenbach, R.C. Chatelier, H.J. Griesser, Correlation of the Nitrogen 1s and Oxygen 1s XPS Binding Energies with Compositional Changes During Oxidation of Ethylene Diamine Plasma Polymers, Surf. Interface Anal. 24 (1996) 611-619. doi:10.1002/(SICI)1096-9918(19960916)24:9<611::AID-SIA169>3.0.CO;2-7.

[41] T.R. Gengenbach, H.J. Griesser, Aging of 1,3-diaminopropane plasma-deposited polymer films: Mechanisms and reaction pathways, J. Polym. Sci. Part Polym. Chem. 37 (1999) 2191-2206. doi:10.1002/(SICI)1099-0518(19990701)37:13<2191::AIDPOLA34>3.0.CO;2-F.

[42] S. Golczak, A. Kanciurzewska, M. Fahlman, K. Langer, J.J. Langer, Comparative XPS surface study of polyaniline thin films, Solid State Ion. 179 (2008) 2234-2239. doi:10.1016/j.ssi.2008.08.004.

[43] A.P. Monkman, G.C. Stevens, D. Bloor, X-ray photoelectron spectroscopic investigations of the chain structure anddoping mechanisms in polyaniline, J. Phys. Appl. Phys. 24 (1991) 738-749. doi:10.1088/0022-3727/24/5/017.

[44] J.B. Metson, Charge compensation and binding energy referencing in XPS analysis, Surf. Interface Anal. 27 (1999) 1069-1072. doi:10.1002/(SICI)10969918(199912)27:12<1069::AID-SIA677>3.3.CO;2-1.

[45] H. Sangodkar, S. Sukeerthi, R.S. Srinivasa, R. Lal, A.Q. Contractor, A Biosensor Array Based on Polyaniline, Anal. Chem. 68 (1996) 779-783. doi:10.1021/ac950655w. 